\title{
A Comparative Study of Mental Health of Sportspersons and Non-Sportspersons of Punjab
}

\author{
Dr. Gurvir Singh ${ }^{1}$, Lalit Mohan Tiwari ${ }^{2}$ \\ ${ }^{1}$ Assistant Professor, Sri Guru Granth Sahib World University, Fatehgarh Sahib Punjab, India \\ ${ }^{2}$ Assistant Professor, Department of Physical Education, Punjabi University Patiala, Punjab, India
}

\begin{abstract}
Mental health is an index which shows the extent to which the person has been able to meet his environmental demandssocial, emotional or physical. The purpose of the study was to " compare the Mental Health among Sports persons and Non Sports persons of Punjab." A total of 400 male constituted the sample for the investigator. This sample was selected from the Punjabi University Patiala and its affiliated College. The subjects were divided into two groups on the basis of Sports persons $(n=200)$ and nonsportsman $(n=200)$.The age range of 18-26 years was taken as a subject for the present study. Mental health inventory developed by Jagdish and Srivastava (1996) was used to measure mental health. The inventory consists of 56 items, including 32 false keyed (negative) and 24 true keyed (positive) statements. It was hypothesized that there will be no significant difference between Sports persons and non-sportspersons in term of Mental health status. Hence, the formulated hypothesis that "there will be no significant difference between Sports persons and non-Sports persons on mental health variable was rejected at 0.05 level of significance. The data collected on mental health component was analyzed by independent " $t$ " test. The level of significance for testing the hypothesis was set at 0.05 level of confidence. The results have shown that there was a significant difference between Sports persons and non-Sports persons in term of mental health score arranged by mental health inventory questionnaire $(d f=398, t=6.736, P<.05)$. The higher mean score of Sports persons $(M=144.95)$ on mental health variable than the non Sports persons $(M=136.85)$ indicates that Sports persons report higher mental health indexed in shape of life e.g. positive self evaluation perception of reality integration of personality autonomy group oriented attitude environmental competence overall than their non-Sports persons counterparts.
\end{abstract}

Keywords: Mental Health, sports person, Mental health inventory

\section{Introduction}

Mental health is an index which shows the extent to which the person has been able to meet his environmental demandssocial, emotional or physical. However, when he finds himself trapped in a situation, he does not have matching coping strategies to deal with it effectively, he gets himself mentally strained. This mental strain is generally reflected in symptoms like anxiety, tension, restlessness or hopelessness among others. If it is felt for too long and too extensively by the person, these symptoms may take a definite form (or get „,syndromized $\left.{ }^{\text {ee}}\right)$, representing a given illness. Mental health, therefore, should not be confused with mental illness; it is a study of pre-illness mental condition of the person. Mental health, as such, represents a psychic condition which is characterized by mental peace, harmony and content. It is identified by the absence of disabling and debiliting symptoms, both mental and somatic in the person. Mental health is the full and harmonious functioning of the whole personality. The definition of mental health in terms of the functioning of personality makes it relative to time, setting and circumstances of the socio-cultural group. Age and mental health has a very close relationship. As it deals with adjustment problems at every stage of life; it helps a person to adjust his/her ways of thinking, feeling, behaving and attitudes in accordance with his/her make up, the environment and the newer developments of players.

Mental health is the ability to handle everyday demands and situations including the emotional upsets without excessive stress and strain. A mentally healthy person therefore has a sense of well-being and functions effectively in life. He can work regularly, think clearly, manage his emotions, enjoy life and keep on reasonable good terms with most people including himself. Mental health is a state of good adjustment with a subjective state of well being, zest for living and the feeling that one is exercising his talents and abilities. Mental health refers to the all round well being of an individual. The World Health Organization (2001) has identified four aspects of an individual ${ }^{\text {ee }}$ s total health viz. physical, mental, social and spiritual. Sound mind has a sound body and vice versa. Thus, body and mind are intimately interconnected. If either of the two goes wrong, it directly affects the other. As a result, the total health of an individual goes wrong. Virender et al. (2011) conducted a study on "Comparative Study of Mental Health Va riables of Senior National Level Players of Combat Games". The conclusions stated that National level wushu and boxing players having equal level of mental health.of mental health.

\section{Delimitations of the study}

- Study was delimited to psychological variables of mental health.

- The study was delimited to Sports persons and non Sports persons of Punjabi University, Patiala.

- Only 200 male Sports persons and 200 non Sports persons of Punjab were selected for the investigation.

\section{Objectives of the Study}

The main objective was to compare the Mental Health status between Sports persons and non-Sports persons. 


\section{International Journal of Science and Research (IJSR) \\ ISSN (Online): 2319-7064 \\ Index Copernicus Value (2013): 6.14 | Impact Factor (2015): 6.391}

\section{Hypothesis}

It was hypothesized that There will be no significant difference between Sports persons and Non Sports persons in term of Mental health status.

\section{Methodology}

\section{Sampling}

A total of 400 male constituted the sample for the investigator. This sample was selected from the Punjabi University, Patiala and its affiliated College. The subjects were divided into two groups on the basis of Sports persons $(n=200)$ and non-sportsman $(n=200)$. The age range of 18-26 years was taken as a subject for the present study.

\section{Tool Used}

The investigator has used M.H.I questionnaire for the present study.

\section{Mental Health Inventory}

Mental health inventory developed by Jagdish and Srivastava (1996) was used to measure mental health. The inventory consists of 56 items, including 32 false keyed (negative) and 24 true keyed (positive) statements. The reliability of the inventory was determined by split half method using odd even procedure. The reliability coefficients of different dimensions of mental health inventory were found to be more than 0.70 . The reliability coefficient of overall inventory was 0.73 . The construct validity of inventory was determined by finding out coefficient of correlation between scores of mental health inventory. Construct validity of the inventory is determined by finding coefficient of correlation between scores on mental health inventory and general health questionnaire (Gold Berg, 1978). It was found to be .54. It is not worthy here that high score on the general health questionnaire indicates poor mental health. The inventory was validated against personal "Adjustment" scale (A scalescale of S.D. inventory) developed Pestoryee (1973). The two inventory scores yield positive correlation of .57 revealing moderate validity.

\section{Statistical Analysis}

" $t$ " test has been applied to find out the significant difference. Level of significance was set at 0.05 .

\section{Findings}

Table 1: „t'-value for Sports persons and Non-Sports persons with Respect to their Mean Scores on Mental Health Variable

\begin{tabular}{|c|c|c|c|c|}
\hline $\begin{array}{c}\text { Sr. } \\
\text { No. }\end{array}$ & Variable & $\begin{array}{c}\text { Group-I Sports } \\
\text { persons }\end{array}$ & $\begin{array}{c}\text { Group-II } \\
\text { Non-Sports persons }\end{array}$ & t-value \\
\hline \multirow{2}{*}{1} & Mental & $\mathrm{M}=144.95$ & $\mathrm{M}=136.85$ & \\
& Health & $\mathrm{SD}=11.18$ & $\mathrm{SD}=12.80$ & $\mathbf{6 . 7 3 6 *}$ \\
\hline
\end{tabular}

*Significant at $\mathrm{P}<.05$ level of confidence.

Table 1 indicate that there was a significant difference between Sports persons and non-Sports persons in term of mental health score arranged by mental health inventory questionnaire $(\mathrm{df}=398, \mathrm{t}=6.736, \mathrm{P}<.05)$. The higher mean score of Sports persons $(\mathrm{M}=144.95)$ on mental health variable than the non Sports persons $(M=136.85)$ indicates that Sports persons report higher mental health indexed in shape of life e.g. positive self evaluation perception of reality integration of personality autonomy group oriented attitude environmental competence overall than their non-Sports persons counterparts.

Hence, the formulated hypothesis that "there will be no significant difference between Sports persons and nonSports persons on mental health variable was rejected at 0.05 level of significance.

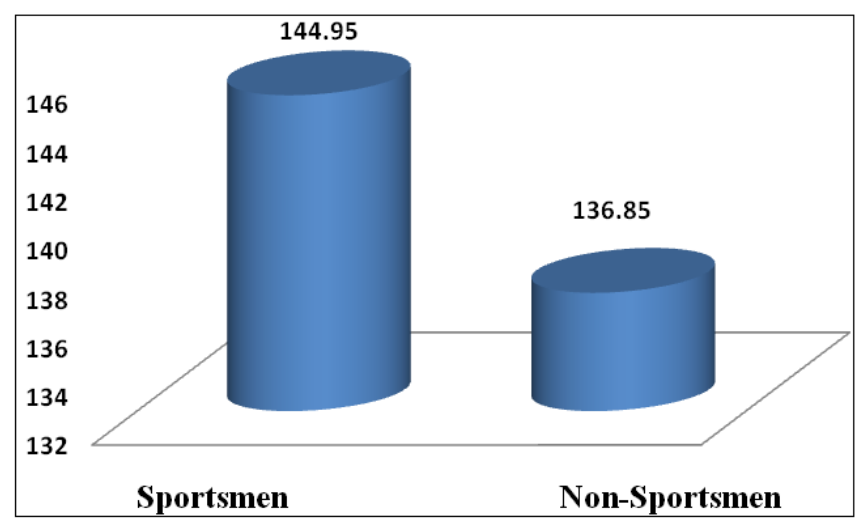

Figure 1: Comparison of Means Value of Mental Health Score

\section{Conclusion}

Sports persons have been found better in mental health status in comparison to non-Sports persons. Sports persons report higher mental health indexed in shape of life e.g. positive self evaluation perception of reality integration of personality autonomy group oriented attitude environmental competence overall than their non-Sports persons counterparts.

\section{References}

[1] Jagdish \& Srivastava, A. K. (1996). Manual of Mental Health Inventory. Manovaigyanik Parikshan Sansthan, Vranasi, pp. 1-9.

[2] Shivani (2010) "Role of Globalization in Promotion of Health and Mental Health", Abstract Book, $5^{\text {th }}$ International Conference on Health, Education and Culture in Globalization Process, Punjab University Chandigarh, India, Vol.I, (p.55).

[3] Sangeeta, et al. (2007) "Impact of Yoga on Mental Health of Visually Challenged Adolescents", Journal of Sports and Sports Sciences, Vol.30, No.3, (pp.19-25).

[4] Shyam Narayan Singh and Singh V. (2010) "Mental Health: A Comparative Study Between Married and Unmarried Equestrian Players of Armed and Police Forces", International Journal of Physical Education, Vol.3, No.1\&2 (pp.9-11).

[5] Sharma Anita (2009) "Environment and Mental Health", Souvenir Refresher Course, UGC- Academic Staff College, Punjab University, Shimla, Vol.XIII, No.1 (pp.45-51).

[6] Nguyen, Dad Quynth (1996) “Chinese Students News of Mental Health and their Relation to Coping Strategies, 


\section{International Journal of Science and Research (IJSR) \\ ISSN (Online): 2319-7064}

Index Copernicus Value (2013): 6.14 | Impact Factor (2015): 6.391

Well Being and Acculturation", University of Cincinnati (0045) Degree : Ph.D. (pp.166).

[7] Nalluri Shinivasa Rao (2011) "A Study on Physical Efficiency, Mental Health and Intelligence of Urban and Rural School Children of Krishna District in Andhra Pradesh", Abstract Book 21 $1^{\text {st }}$ National Conference of Sports Psychology: Acharya Nagarjuna University, Nagar Juanagar, Guntur, Andhra Pradesh, Vol.1, No.1 (p.32).

[8] Kumar, Virender et al. (2011) "Comparative Study of Mental Health Variable of Senior National Player of Combat Games", Shodh-Drishti, Journal of All Research, Vol.II, No.1, (pp.186-188).

[9] Keyes (2002) "The Mental Health Continues", Journal of Health and Social Behaviour, 43 (pp.200-206).

[10] Keyes (2003) "Complete Mental Health, An Agenda for the $21^{\text {st }}$ Century, In C.L.M. Keyes and J. Haidt (Eds), Flourishing", Positive Psychology and the Life WellLived (Journal of Health and Social Behaviour, pp.293312). 